\title{
Correction to: adjacent level disease-background and update based on disc replacement data
}

\author{
I. David Kaye ${ }^{1}$ • Alan S. Hilibrand ${ }^{1}$
}

Published online: 18 October 2017

(C) Springer Science+Business Media, LLC 2017

Correction to: Curr Rev Musculoskelet Med (2017) 10(2):147-152

https://doi.org/10.1007/s12178-017-9396-5

This article was published and transmitted with the lead author's name listed incorrectly in the citation. The correct citation is, in full:

Kaye, I.D. \& Hilibrand, A.S. Curr Rev Musculoskelet Med (2017) 10: 147.

https://doi.org/10.1007/s12178-017-9396-5.

The online version of the original article can be found at https://doi.org/ 10.1007/s12178-017-9396-5

I. David Kaye

iandavid.kaye@gmail.com

1 Rothman Institute at Thomas Jefferson University Hospital, 925

Chestnut Street, Philadelphia, PA 19107, USA 